\title{
Inhibition of Microbial Pyrite Oxidation by PropS-SH for the Control of Acid Mine Drainage
}

\author{
Zan Luo ${ }^{1}$, Yun Liu ${ }^{l, *}$, Runliang $\mathrm{Zhu}^{2}, \mathrm{Xin} \mathrm{Hu}^{\mathrm{l}}$ \\ ${ }^{1}$ Department of Environmental Science and Engineering, Xiangtan University, Xiangtan 411105, \\ China \\ ${ }^{2}$ Key Labortory of Mineralogyand Metallogeny, Guangdong Provincial Key Laboratory of Mineral \\ Physics and Material Research \& Development, Guangzhou Institute of Geochemistry, Chinese \\ Academy of Sciences, Guangzhou 510640, China \\ *E-mail: liuyunscut@163.com
}

doi: $10.20964 / 2016.08 .59$

Received: 6 May 2016 / Accepted: 21 June 2016 / Published: 7 July 2016

\begin{abstract}
Acidithiobacillus ferrooxidans, an acidophilic sulfur and iron-oxidizing microorganism, plays an important role in the oxidation of $\mathrm{FeS}_{2}$ and the formation of acid mine drainage (AMD). In this study, the stability of $\gamma$-mercaptopropyltrimethoxysilane(PropS-SH) treated pyrite in the presence of Acidithiobacillus ferrooxidans was investigated by electrochemical techniques in conjunction with bioleaching approach. In addition, the chemical and morphological characteristics of pyrite before and after coated by PropS-SH were analyzed with X-ray photoelectron spectrometer (XPS) and contact angle tests. The results from electrochemical tests indicated that the coating of PropS-SH significantly decreased electrochemical activity of pyrite in bioleaching solutions. The results of bioleaching experiments showed that PropS-SH coating could effectively suppress the release of $\mathrm{S}$ and Fe species from pyrite and inhibit the growth of bacteria. These results were attributed to the formation of a hydrophobic layer on pyrite surface by chemisorption of PropS-SH which could limite the contact of bacteria with pyrite.
\end{abstract}

Keywords: pyrite; Acid mine drainage; inhibition; Acidithiobacillus ferrooxidans; $\gamma$ mercaptopropyltrimethoxysilane (PropS-SH); Electrochemical technique.

\section{FULLTEXT}

(C) 2016 The Authors. Published by ESG (www.electrochemsci.org). This article is an open access article distributed under the terms and conditions of the Creative Commons Attribution license (http://creativecommons.org/licenses/by/4.0/). 